\title{
Academic stress and self-esteem among rural and urban adolescents
}

\author{
Pinki, Priyanka and Sushma Kaushik
}

Received: 04.02.2020; Revised: 16.03.2020; Accepted: 01.05.2020

See end of the paper for authors' affiliations

\section{Pinki}

Department of Human

Development and Family

Studies, College of Home

Science, C.C.S. Haryana

Agricultural University, Hisar

(Haryana) India

Email : pinkibama1007@gmail.

com
ABSTRACT : Academic stress is a mental distress with respect to some anticipated frustration associated with academic failure or even awareness of the possibility of such failure. Selfesteem is that subjective judgment by which people make their potential to face life's challenges to recognize, understand and also solve the problems, and their right to achieving happiness, and be given respect. The study was undertaken in rural and urban area of Haryana state. Hisar district and village Kharkara was taken in order to meet the sample requirement i.e. 50 adolescents from rural area and 50 from urban area thus making a total sample of 100 adolescents ranging in 16-18 years of age group. The scale used for the study was academic stress scale by Rao (2012) used to assess academic stress and self-esteem inventory by Prasad and Thakur (1977). The finding elucidates that maximum number of respondents have moderate level of academic stress and found significant difference in both rural and urban area.Data regards to self-esteem found that maximum respondents have positive level of self-esteem followed by balanced level and self-esteem was significantly and negatively correlated with academic stress.

KEY WORDS: Academic stress, Self-esteem

- HOW TO CITE THIS PAPER : Pinki, Priyanka and Kaushik, Sushma (2020). Academic stress and selfesteem among rural and urban adolescents. Asian J. Home Sci., 15 (1) : 80-86, DOI: 10.15740/HAS/AJHS/ 15.1/80-86. Copyright@ 2020: Hind Agri-Horticultural Society. 